\title{
In vivo neutralization of inflammatory cytokines might not be necessary for regulatory T-cell immunotherapy
}

\section{Manuela Battaglia and Maria-Grazia Roncarolo}

We thank Dr Bayry and colleagues for their comments on our recently published Review $^{1}$. The authors argue that the naturally occurring $\mathrm{CD} 4^{+} \mathrm{CD} 25^{+}$regulatory $\mathrm{T}\left(\mathrm{T}_{\mathrm{Reg}}\right)$-cell population is defective in rheumatoid arthritis and possibly in other autoimmune inflammatory diseases (such as multiple sclerosis and type 1 diabetes) and that therefore adoptive immunotherapy with defective $\mathrm{T}_{\mathrm{Reg}}$ cells isolated from autoimmune patients and expanded ex vivo is unlikely to be efficacious. It is important to highlight that, to date, there is still no formal proof that in vivo $\mathrm{T}_{\mathrm{Reg}}$ cells have an intrinsic defect in chronic inflammatory and autoimmune diseases. As highlighted in our Review, studies investigating the percentages and function of circulating $\mathrm{CD} 4^{+} \mathrm{CD} 25^{+}$ $\mathrm{T}$ cells in patient samples have led to conflicting data. These discrepancies might be because the $\mathrm{CD} 4{ }^{+} \mathrm{CD} 25^{+} \mathrm{T}$-cell population can comprise activated $\mathrm{T}$ cells that do not display regulatory function, and therefore do not represent a pure $\mathrm{T}_{\mathrm{Reg}}$-cell population. This is the case in studies performed in patients with type 1 diabetes. The existence of $\mathrm{T}_{\mathrm{Reg}}$ cells with defective suppressor function in patients with type 1 diabetes has been demonstrated by some investigators ${ }^{2-4}$, whereas others ${ }^{5}$ have shown that $\mathrm{T}_{\text {Reg }}$ cells from such patients are as suppressive as those from normal healthy donors. This latter study was carried out using $\mathrm{CD} 4^{+} \mathrm{CD} 25^{\mathrm{hi}}$ $\mathrm{T}$ cells that were isolated using a fluorescence-activated cell sorter (FACS) ${ }^{5}$, whereas the former studies used magnetic beads to isolate $\mathrm{CD}^{+} \mathrm{CD} 25^{+} \mathrm{T}$ cells ${ }^{2-4}$. It is therefore possible that patients with type 1 diabetes do not have defective $\mathrm{T}_{\mathrm{Reg}}$ cells per se, but instead have a higher frequency of contaminating effector T cells in bead-sorted $\mathrm{CD} 4{ }^{+} \mathrm{CD} 25^{+}$ $\mathrm{T}$ cells compared with those of healthy individuals. The reported increase in expression of activation markers (such as CD69 and HLA-DR) on $\mathrm{CD}^{+}$and $\mathrm{CD} 8^{+} \mathrm{T}$ cells from patients with type 1 diabetes, both at onset and during the course of the disease, is consistent with this hypothesis ${ }^{6,7}$. So, only highly purified FACS-sorted CD $4{ }^{+} \mathrm{CD} 25^{\text {hi }} \mathrm{T}$ cells from patients with type 1 diabetes display suppressive function in vitro ${ }^{5}$. Importantly, we have shown that ex vivo culture of $\mathrm{T}_{\mathrm{Reg}}$ cells isolated from type 1 diabetic patients in the presence of rapamycin leads to expanded cells with in vitro regulatory activity that is identical to those of normal donors. These data suggest that, for cells from type 1 diabetic subjects, specific cell-culture conditions can selectively expand functional $\mathrm{T}_{\text {Reg }}$ cells over contaminating effector $\mathrm{CD} 4{ }^{+} \mathrm{CD} 25^{+} \mathrm{T}$ cells ${ }^{8}$.

As an alternative to the ex vivo expansion of $\mathrm{T}_{\mathrm{Reg}}$ cells we also propose in our Review the use of adoptive immunotherapy with inducible regulatory $\mathrm{T}$ cells, such as $\mathrm{T}_{\mathrm{R}} 1$ cells, which are generated in vitro in the presence of the antigen and interleukin-10. This approach overrides the need for isolating and expanding $\mathrm{T}_{\mathrm{Reg}}$ cells from patients with ongoing acute and chronic disease ${ }^{1}$.

We agree with Dr Bayry and colleagues that it is still completely uncertain whether adoptive transfer of ex vivo expanded or generated regulatory $\mathrm{T}$ cells per se is sufficient to downregulate inflammation and revert active diseases. We indeed suggest that "Regulatory T-cell-based immunotherapy should not be envisaged as an all-or-nothing approach to re-establish immunological tolerance on its own." ${ }^{\text {An }}$ alternative approach that combines regulatory T-cell-based adoptive immunotherapy with other therapeutic interventions that are able to counteract the non-tolerogenic inflammatory milieu and the function of activated effector $\mathrm{T}$ cells might result in a better clinical outcome.

The different method proposed by Bayry and colleagues to first induce functionally fit regulatory $\mathrm{T}$ cells in vivo in the patients followed by their ex vivo expansion could also be considered. The observations that treatment of rheumatoid arthritis patients with tumour-necrosis factor blockade leads to a significant increase in the number of circulating $\mathrm{T}_{\mathrm{Reg}}$ cells ${ }^{9,10}$ and to the generation of a newly differentiated population of regulatory $\mathrm{T}$ cells ${ }^{11}$ are clearly interesting. However, these cells do not mediate longterm tolerance in vivo ${ }^{12}$. Furthermore, the demonstration that these in vivo re-fit regulatory $\mathrm{T}$ cells can be isolated and expanded in vitro while maintaining their regulatory activity is still missing.

Manuela Battaglia is at the San Raffaele Telethon Institute for Gene Therapy (HSR-TIGET), Via Olgettina 58, 20132 Milan, Italy and at the San Raffaele Scientific Institute, Immunology of Diabetes Unit, 20132 Milan, Italy

Maria-Grazia Roncarolo is at the San Raffaele Telethon Institute for Gene Therapy (HSR-TIGET), Via Olgettina 58 , 20132 Milan, Italy and at the Vita-Salute San Raffaele University, 20132 Milan, Italy doi: 10.1038/nri2138-c2

1. Roncarolo, M. G. \& Battaglia, M. Regulatory T-cell immunotherapy for tolerance to self antigens and alloantigens in humans. Nature Rev. Immunol. 7 585-598 (2007).

2. Brusko, T. M., Wasserfall, C. H., Clare-Salzler, M. J., Schatz, D. A. \& Atkinson, M. A. Functional defects and the influence of age on the frequency of CD4 CD25+ T-cells in type 1 diabetes. Diabetes $\mathbf{5 4}$, 1407-1414 (2005).

3. Glisic-Milosavljevic, S. et al. At-risk and recent-onset type 1 diabetic subjects have increased apoptosis in the CD4 ${ }^{+} \mathrm{CD} 25+$ T-cell fraction. PLOS ONE 2, e 146 (2007).

4. Lindley, S. et al. Defective suppressor function in $\mathrm{CD} 4{ }^{+} \mathrm{CD} 25^{+} \mathrm{T}$-cells from patients with type 1 diabetes. Diabetes 54, 92-99 (2005).

5. Putnam, A. L., Vendrame, F., Dotta, F. \& Gottlieb, P. A $\mathrm{CD} 4{ }^{+} \mathrm{CD} 25^{\text {high }}$ regulatory $\mathrm{T}$ cells in human autoimmune diabetes. J. Autoimmun. 24, 55-62 (2005).

6. Gessl, A. \& Waldhausl, W. Increased CD69 and human leukocyte antigen-DR expression on T lymphocytes in insulin-dependent diabetes mellitus of long standing. J. Clin. Endocrinol. Metab. 83, 2204-2209 (1998).

7. Roncarolo, M. G. et al. Interleukin-2 production and interleukin-2 receptor expression in children with newly diagnosed diabetes. Clin. Immunol. Immunopathol. 49, 53-62 (1988).

8. Battaglia, M. et al. Rapamycin promotes expansion of functional $\mathrm{CD} 4{ }^{+} \mathrm{CD} 25^{+} \mathrm{FOXP3}+$ regulatory $\mathrm{T}$ cells of both healthy subjects and type 1 diabetic patients. J. Immunol. 177, 8338-8347 (2006).

9. Ehrenstein, M. R. et al. Compromised function of regulatory $\mathrm{T}$ cells in rheumatoid arthritis and reversal by anti-TNF $\alpha$ therapy. J. Exp. Med. 200, 277-285 (2004).

10. Valencia, X. et al. TNF downmodulates the function of human CD4+CD25 hi T-regulatory cells. Blood 108, 253-261 (2006)

11. Nadkarni, S., Mauri, C. \& Ehrenstein, M. R. Anti-TNF- $\alpha$ therapy induces a distinct regulatory $T$ cell population in patients with rheumatoid arthritis via TGF- $\beta$. J. Exp. Med. 204, 33-39 (2007)

12. Buch, M. H., Marzo-Ortega, H., Bingham, S. J. \& Emery, P. Long-term treatment of rheumatoid arthritis with tumour necrosis factor $\alpha$ blockade: outcome of ceasing and restarting biologicals. Rheumatology (Oxford) 43, 243-244 (2004). 